\title{
COMUNICAÇÃO E GEOGRAFIA: DINÂMICAS DA CIRCULAÇÃO DE INFORMAÇÕES NO TERRITÓRIO BRASILEIRO
}

\author{
Beatriz Lorena da Silva Pereira*, Theo Soares de Camargo, André B. Pasti
}

\begin{abstract}
Resumo
Este projeto tem como objetivo mapear e analisar os círculos de informações no território brasileiro, considerando o alcance efetivo dessas informações. Para tanto, desenvolveram-se duas investigações: a análise do consumo de informações nos espaços opacos da globalização no Brasil e o estudo da rede e do alcance das informações da comunicação pública brasileira, baseada na Empresa Brasil de Comunicação (EBC).
\end{abstract}

\section{Palavras-chave:}

circulação de informações; globalização; comunicação pública.

\section{Introdução}

O presente trabalho pretende contribuir para o entendimento da produção e circulação de informações no território brasileiro. Para isso, foram estabelecidos dois objetivos: (a) Analisar como a população que vive em municípios de baixa densidade informacional e técnica do território brasileiro se relaciona com os meios de comunicação e consome informações; (b) Analisar a rede e o alcance das informações dos meios de comunicação pública no Brasil, sobretudo a Empresa Brasil de Comunicação (EBC).

\section{Resultados e Discussão}

Para Santos e Silveira ${ }^{1}$, não existe um espaço global, mas "espaços da globalização". É possível entender essa questão a partir da diferenciação de espaços "luminosos" e "opacos" da globalização, distintos em função da conexão (ou não) às redes globais e da densidade de tecnologia e de informação desses espaços. Como se estabelece a circulação de informações nesses espaços opacos do território brasileiro? Para a análise, partiu-se da regionalização dos quatro Brasis - Amazônia, Nordeste, Centro-Oeste e Região Concentrada. A partir de então, buscou-se compreender as dinâmicas de consumo de informações nas regiões de menor presença do meio técnicocientífico-informacional - menos conectadas à globalização. Ainda que com grande heterogeneidade entre as regiões, observa-se, a partir da Pesquisa

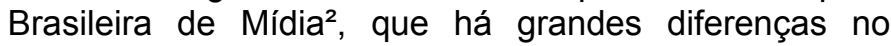
consumo de informações nesses espaços opacos em comparação aos principais centros urbanos integrados às redes globais. Desde os equipamentos, como a prevalência de antenas parabólicas, o domínio da televisão aberta, o baixo acesso à internet e o consumo inferior de jornais e revistas impressas. Foram produzidos trabalhos técnicos de síntese dessas características. Busca-se, ainda, para o futuro, construir uma metodologia de análise para dar conta dos espaços opacos presentes na região concentrada.

De outro lado, buscou-se analisar outras lógicas de comunicação diferentes da comercial. Assim, realizou-se um amplo levantamento bibliográfico para as definições e distinções entre modelos e sistemas de comunicação, até definir o foco na organização da comunicação pública, que diz respeito à interação e ao fluxos de informação relacionados a temas de interesse coletivo ou financiamento público. No Brasil, a EBC surge em 2007, com sede em Brasília. Contava, em 2015, com cerca de 2600 funcionários e, em sua organização, conta com um Conselho Curador que garante à população participação nas estratégias da empresa. A TV Brasil, da EBC, é conhecida por $37 \%$ da população brasileira, segundo a Pesquisa Brasileira de Mídia. Foram realizados mapeamentos e quadros da rede e do alcance de suas informações.

\section{Considerações finais}

Analisar as dinâmicas de circulação de informações no espaço atualmente exige o entendimento de que poucos grupos, sobretudo grandes empresas, detêm o controle da produção e circulação de grande parte da comunicação, no mundo e no Brasil. Segundo Santos ${ }^{3}$, a periferia acaba se tornando ainda mais periférica, seja porque não dispõem totalmente dos novos meios, seja porque escapa a possibilidade de controle. Assim, é vital compreender como se dá essa desigualdade na comunicação também internamente ao território brasileiro, nos espaços opacos da globalização. Do mesmo modo, é importantíssimo compreender as alternativas à informação dominante das grandes empresas - como é o caso da comunicação pública no Brasil. A partir da redução dessas desigualdades e da circulação de outros sentidos, podemos pensar na produção de uma outra globalização, mais humana e democrática.

\section{Agradecimentos}

Ao programa PIBIC-EM pelo financiamento e ao COTUCA pelo apoio institucional.

BRASIL/Secom. Pesquisa brasileira de mídia 2014: hábitos de consumo de mídia pela população brasileira. Brasília: Secom, 2014.

SANTOS, Milton. Por uma outra globalização. RJ: Record: 2000.

SANTOS, Milton; SILVEIRA, María Laura. O Brasil: Território e Sociedade no início do século XXI. Rio de Janeiro: Record, 2001. 